\title{
Autonomic Reflexes and Vascular Reactivity in Experimental Scurvy in Man
}

\author{
François M. Abboud, James Hood, Robert E. Hodges, and \\ Howard E. MAYER \\ From the Department of Medicine, University of Iowa, College of Medicine, \\ Iowa City, Iowa 52240
}

\begin{abstract}
A B S T R A C T Ascorbic acid is a required cofactor in the conversion of dopamine to norepinephrine in vitro, and the deficiency of this vitamin in guinea pigs is associated with degeneration of autonomic ganglion cells and with cardiac supersensitivity to norepinephrine. Because of these findings, we tested the hypothesis that ascorbic acid deficiency in man alters autonomic cardiovascular reflexes and vasomotor responses to adrenergic stimuli. We studied five normal volunteers who had been deprived of ascorbic acid for a period of 3 months; they had developed symptoms and signs of scurvy and their plasma levels of ascorbic acid averaged $0.178 \pm$ se 0.07 $\mathrm{mg} / 100 \mathrm{ml}$. We repeated the studies after giving the subjects vitamin $C$ for a period of 4 months; they had become asymptomatic and their plasma ascorbic acid had increased to an average of $1.68 \pm 0.151 \mathrm{mg} / 100 \mathrm{ml}$.
\end{abstract}

Blood flow to the left forearm (plethysmograph), arterial and central venous pressures, and heart rate were measured before and after exposure of the lower half of the body to subatmospheric levels of pressure and before and after intravenous and intra-arterial (left brachial artery) infusions of norepinephrine and tyramine.

Average values of blood flow $(7.9 \pm 1.4 \mathrm{ml} / \mathrm{min}$ per $100 \mathrm{ml})$, arterial pressure $(91.2 \pm 4.6 \mathrm{~mm} \mathrm{Hg}$ ), heart rate $(68 \pm 4.4$ beats $/ \mathrm{min}$ ), central venous pressure (6.1 $\pm 1.1 \mathrm{~mm} \mathrm{Hg}$ ), and plasma catecholamines $(0.68 \pm 0.20$ $\mu \mathrm{g} /$ liter) obtained during ascorbic acid deficiency were not altered significantly after correction of the deficiency. Vasoconstrictor responses to intra-arterial norepinephrine and tyramine were augmented after vitamin repletion. During ascorbic acid deficiency, four subjects had

This work was presented at the 41st Annual Meeting of the Central Society for Clinical Research, Chicago, 1 November 1968. A preliminary report has appeared in abstract form (1).

Received for publication 29 July 1969 and in revised form 26 September 1969. reduced responsiveness of resistance vessels of the forearm to lower body negative pressure as compared to the responsiveness observed after vitamin repletion. Reflex tachycardia during lower body negative pressure and reflex bradycardia during the pressor responses to intravenous tyramine and norepinephrine were similar during the two studies.

The results suggest that the decreased vascular responsiveness to intra-arterial norepinephrine and tyramine and to lower body negative pressure during ascorbic acid deficiency is caused by a defect in the ability of resistance vessels to constrict in response to adrenergic stimuli. Ascorbic acid deficiency in man does not interrupt autonomic reflexes and does not appear to cause significant depletion of endogenous norepinephrine.

\section{INTRODUCTION}

Several experimental observations indicate that ascorbic acid deficiency may be associated with abnormal cardiovascular responses. In 1947 Lee and Lee (2) demonstrated in the mesenteric vascular bed of scorbutic guinea pigs decreased reactivity of vessels less than $100 \mu$ to topically applied epinephrine. Thoa and Booker (3) reported in 1963 that increases in arterial pressure and in myocardial contractile force in response to norepinephrine were augmented in scorbutic guinea pigs and more recently Thoa, Wurtman, and Axelrod (4) proposed that this supersensitivity to norepinephrine may be related to decreased binding and inactivation of circulating norepinephrine by the heart. On the other hand, observations on atria isolated from scorbutic pigs failed to show supersensitivity to norepinephrine (5).

Ascorbic acid appears to be an essential cosubstrate for the beta-hydroxylation of dopamine to norepinephrine $(6,7)$ and the work of Sulkin and Sulkin (8) on the ultrastructure of autonomic ganglion cells indicates 
that ascorbic acid is necessary for the integrity of these cells.

The foregoing considerations led us to test the hypothesis that ascborbic acid deficiency in man alters cardiovascular reflexes and vasomotor responses to adrenergic stimuli.

\section{METHODS}

After approval of appropriate committees of the College of Medicine and of the Board of Supervisors of the State Prison of Fort Madison, Iowa, five healthy prisoners who volunteered for the study were admitted to the metabolic ward where intense medical and nursing supervision were provided. The subjects' diet consisted of a liquid formula which did not contain vitamin C (Table I) and their caloric intake was adjusted so that each subject maintained constant weight throughout the period of depletion. At the end of approximately 90 days, plasma levels of ascorbic acid had decreased markedly and the men had clinical manifestations of scurvy (9) (Table II). This period of depletion will reduce the total body pool of ascorbic acid to less than $20 \%$ of normal (10). Repletion was then begun by allowing the subjects to eat a solid diet containing 2.5 $\mathrm{mg}$ of ascorbic acid/day and by supplementing the diet with vitamin $\mathrm{C}$ in different amounts for each one of the five subjects as shown in Fig. 1. The first study was carried out during the first week of repletion and a second study was carried out approximately 4 months later (Fig. 1).

The subjects were lying lightly clothed and comfortably supine on a couch. Room temperature was $82^{\circ} \mathrm{F}$. A polyethylene cannula $(1.2 \mathrm{~mm}$ od) was introduced into the left brachial artery and connected through stopcocks to a pressure transducer (Statham Instruments, Inc., Los Angeles, Calif., P23AA) for measurement of arterial pressure and to syringes for infusion of drugs. A 24 in, 17 gauge Intracath (C. R. Bard, Inc., Murray Hill, N. J.) was inserted through the right antecubital vein and advanced a distance of approximately 14-18 in for measurement of central venous pressure. The venous cannula was connected to another transducer (Statham P23BB) placed at the level

TABLE I

Vitamin C-Free Synthetic Formula*

\begin{tabular}{lc}
\hline \multicolumn{1}{c}{ Ingredients } & Intake \\
\hline & $g /$ day \\
Vitamin-free casein (92\% protein) & 122 \\
Sucrose or Milo oxidized starch & 338 \\
Peanut oil & 64 \\
Cocoa butter & 56 \\
Safflower oil & 13 \\
Iodized salt & 5 \\
Basic mineral and crystine mixture & \\
Basic vitamin mixture (Vitamin C-free) & \\
H ${ }_{2} \mathrm{O}$ (1000-1500 ml) &
\end{tabular}

* 3000 Calories: 15\% Protein, 40\% Fat, and 45\% Carbohydrate. This liquid formula was given through a nasogastric tube. Additional details concerning the composition of the formula with respect to minerals and vitamins have been published (9).
TABLE II

Manifestations of Scurvy at the Time of the First Study

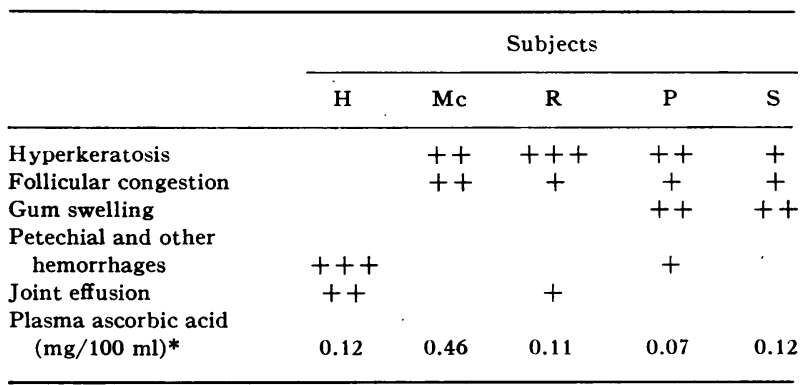

The + signs represent a clinical assessment of the severity of the manifestation.

* After repletion of ascorbic acid over a period of 4 months at the time of the second study (session II), the manifestations had disappeared and the plasma levels of ascorbic acid were $1.84,1.27,2.06,1.38$, and $1.84 \mathrm{mg} / 100$ $\mathrm{ml}$ for subjects $\mathrm{H}, \mathrm{Mc}, \mathrm{R}, \mathrm{P}$, and $\mathrm{S}$ respectively. The rise in plasma levels of vitamin $C$ did not appear to correlate with the amount of supplementation. As shown in Fig. 1, subjects $\mathrm{H}$ and $\mathrm{P}$ received a supplement of ascorbic acid of $4 \mathrm{mg} / \mathrm{day}$, subjects $R$ and $S$ received $64 \mathrm{mg}$, and subject Mc received $128 \mathrm{mg}$.

of right atrium and to syringes for intravenous infusion of drugs.

A strain-gauge plethysmograph compensated for temperature variations (11) was used to measure changes in volume of the forearm. The strands were made of Silastic tubing ( $0.4 \mathrm{~mm}$ ID $0.8 \mathrm{~mm}$ oD) (Dow Corning Corp., Midland, Mich.) filled with mercury. The gauge was applied on the left forearm at a tension of $15 \mathrm{~g}$. The elbow was elevated on foam-padded sand bags and the forearm was slightly flexed and inclined at $45^{\circ}$ to the horizontal plane with the wrist and hand supported by a padded sling. In this position, the veins of the forearm were essentially collapsed and could be distended freely when venous congestion was produced. All measurements were recorded on a direct writing oscillograph (Sanborn Co., Waltham, Mass.). A pneumatic cuff was placed around the distal part of the forearm and inflated to suprasystolic pressures during the measurements. This cuff arrested the circulation to the hand and excluded the contribution of the venous return from the hand to changes in volume of the forearm. A second pneumatic cuff

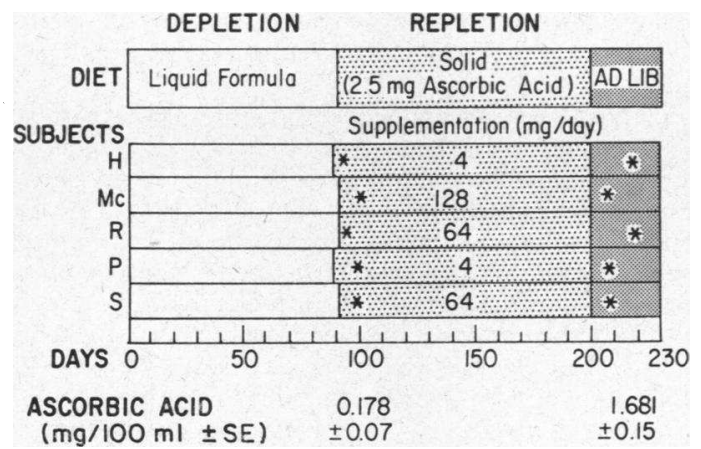

FIgURE 1 The asterisks indicate the times at which the two studies were carried out in each subject. The dietary intake of ascorbic acid was supplemented during the phase of repletion by different daily amounts in each subject as shown in the figure. 
TABLE III

Responses to Lower Body Negative Pressure (LBNP) during the Scorbutic

\begin{tabular}{|c|c|c|c|c|c|c|c|c|c|c|c|}
\hline \multirow[b]{3}{*}{ Subject } & & \multicolumn{5}{|c|}{ FBF } & \multicolumn{5}{|c|}{ BP } \\
\hline & & \multirow[b]{2}{*}{$\mathrm{C}$} & \multicolumn{3}{|c|}{ During LBNP } & \multirow[b]{2}{*}{ After } & \multirow[b]{2}{*}{ C } & \multicolumn{3}{|c|}{ During LBNP } & \multirow[b]{2}{*}{ After } \\
\hline & & & -20 & -40 & -60 & & & -20 & -40 & -60 & \\
\hline & & \multicolumn{5}{|c|}{$\mathrm{ml} / \mathrm{min}$ per $100 \mathrm{ml}$} & \multicolumn{5}{|c|}{$m m \mathrm{Hg}$} \\
\hline \multirow[t]{2}{*}{$\mathbf{H}$} & I & 9.3 & 7.8 & 7.2 & 5.3 & 7.6 & 102 & 102 & 102 & 100 & 105 \\
\hline & II & 7.2 & 5.2 & 6.6 & 5.4 & 9.2 & 107 & 110 & 110 & 100 & 100 \\
\hline \multirow[t]{2}{*}{ Mc } & I & 4.9 & 3.0 & 3.1 & 1.3 & 9.8 & 75 & 73 & 53 & 27 & 65 \\
\hline & II & 4.8 & 3.3 & 3.0 & 2.8 & 9.3 & 75 & 70 & 70 & 68 & 65 \\
\hline \multirow[t]{2}{*}{$\mathbf{R}$} & I & 5.8 & 3.7 & 3.1 & 2.0 & 9.5 & 97 & 95 & 85 & 62 & 68 \\
\hline & II & 5.3 & 3.1 & 4.3 & 2.9 & 8.6 & 92 & 88 & 87 & 80 & 80 \\
\hline \multirow[t]{2}{*}{$\mathrm{P}$} & I & 12.8 & 7.4 & 6.7 & 7.5 & 15.5 & 92 & 94 & 95 & 92 & 92 \\
\hline & II & 9.5 & 6.6 & 8.1 & 8.5 & 19.8 & 75 & 77 & 79 & 70 & 80 \\
\hline \multirow[t]{2}{*}{$\mathbf{S}$} & I & 6.6 & 4.3 & 4.3 & 3.9 & 11.2 & 90 & 90 & 90 & 77 & 80 \\
\hline & II & 5.2 & 4.0 & 4.1 & 2.8 & 8.7 & 97 & 95 & 94 & 78 & 90 \\
\hline \multirow[t]{4}{*}{ Mean \pm SE } & I & 7.9 & $5.2^{*}$ & $4.9^{*}$ & $4.0^{*}$ & $10.7^{*}$ & 91 & 91 & 85 & $72^{*}$ & 82 \\
\hline & & 1.4 & 1.0 & 0.9 & 1.1 & 1.3 & 4.6 & 4.8 & 8.5 & 12.9 & 7.5 \\
\hline & II & 6.4 & $4.4^{*}$ & $5.2^{*}$ & $4.5^{*}$ & $11.0^{*}$ & 89 & 88 & 88 & $79^{*}$ & 83 \\
\hline & & 0.9 & 0.6 & 0.9 & 1.1 & 2.2 & 6.3 & 7.0 & 6.8 & 5.7 & 5.8 \\
\hline
\end{tabular}

Entries represent blood flow to the forearm (FBF), mean arterial blood pressure (BP), calculated vascular resistance in the forearm (Res.), and heart rate (HR). Resistance was estimated from the quotient (arterial pressure - venous pressure)/(forearm blood flow). The values shown were obtained before LBNP (C), during LBNP at $-20,-40$, and $-60 \mathrm{~mm} \mathrm{Hg}$, and at approximately $30 \mathrm{sec}$ after LBNP (After). Each value of FBF represents data from 3 to 6 flow curves. Central venous pressure averaged $6.1 \pm 1.1,2.8 \pm 1.1,1.8 \pm 0.8$, and $1.3 \pm 0.7$ before and during LBNP at $-20,-40$, and $-60 \mathrm{~mm} \mathrm{Hg}$ respectively in session $I$; corresponding values in session II were $6.4 \pm 0.7,2.3 \pm 0.6,1.4 \pm 0.5$, and $0.7 \pm 0.6$.

* The average values were significantly different from control observations by paired $t$ test analyses $(P<0.05)$. Average differences between session I and II were not statistically significant. Immediately after LBNP there was a vasodilator response in the forearm which was transient (Fig. 2) ; all values returned to control levels within $1-1 \frac{1}{2} \mathrm{~min}$.

was placed around the arm proximal to the plethysmograph for venous occlusion. Changes in forearm volume produced by sudden inflation of the venous occlusion cuff were used to measure the rate of blood flow to the forearm (12) (Fig. 2).

A suction box was applied around the lower half of the body to the level of the anterior-superior iliac spine and a plastic sheet enveloped it to provide the seal necessary for maintaining subatmospheric levels of pressure within the box. The box was connected to the hose of a commercial vacuum cleaner and the degree of suction was regulated by adjusting the opening of a slot on the side of the connecting hose. The lower half of the body could thus be exposed to subatmospheric levels of pressure at $-20,-40$, or $-60 \mathrm{~mm}$ $\mathrm{Hg}$ for any desired period of time.

After the subjects had achieved a stable resting state, blood flow to the forearm, arterial pressure, central venous pressure, and heart rate were measured in response to lower body negative pressure (LBNP) and to intra-arterial and intravenous infusions of norepinephrine and tyramine. After obtaining control values, suction was applied to create a negative pressure of $20 \mathrm{~mm} \mathrm{Hg}$ for $3 \mathrm{~min}$; the level of suction was then increased to achieve a pressure of -40 $\mathrm{mm} \mathrm{Hg}$ for a period of $3 \mathrm{~min}$ and $-60 \mathrm{~mm} \mathrm{Hg}$ for 3 additional min before discontinuing suction. Arterial blood samples for measurements of blood gases, $\mathrm{pH}$, hematocrit, and blood levels of catecholamines were obtained before LBNP and during the last $3 \mathrm{~min}$ of LBNP. Responses were also measured during the intra-arterial infusion of two doses of norepinephrine $(0.002$ and $0.004 \mu \mathrm{g} / \mathrm{kg}$ per $\min )$, the intra-arterial infusion of two doses of tyramine $(0.3$ and 0.6 $\mu \mathrm{g} / \mathrm{kg}$ per $\mathrm{min})$, the intravenous infusion of two or three doses of norepinephrine $(0.0375,0.075$, and $0.150 \mu \mathrm{g} / \mathrm{kg}$ per $\min$ ), and finally the intravenous infusion of two doses of tyramine $(12.5$ and $25 \mu \mathrm{g} / \mathrm{kg}$ per $\mathrm{min}$ ). The graded doses of each drug were infused consecutively each for $3 \mathrm{~min}$. Resting periods of $15 \mathrm{~min}$ were allowed between each set of infusions. The doses of norepinephrine are given in terms of the base of $l$-norepinephrine bitartrate which was diluted in $5 \%$ glucose in water and infused at rates of 0.6 and 1.2 $\mathrm{ml} / \mathrm{min}$. The dose of tyramine was given in terms of the salt tyramine sulfate. Responses to the interventions were calculated from observations made during the last minute of each intervention. 
Phase (Session I) and after Repletion of Ascorbic Acid (Session II)

\begin{tabular}{|c|c|c|c|c|c|c|c|c|c|}
\hline \multirow[b]{3}{*}{$\mathrm{C}$} & \multicolumn{3}{|c|}{ Res. } & \multirow[b]{3}{*}{ After } & \multicolumn{5}{|c|}{ HR } \\
\hline & \multicolumn{3}{|c|}{ During LBNP } & & \multirow[b]{2}{*}{$\mathrm{C}$} & \multicolumn{3}{|c|}{ During LBNP } & \multirow[b]{2}{*}{ After } \\
\hline & -20 & -40 & -60 & & & -20 & -40 & -60 & \\
\hline & \multicolumn{3}{|c|}{$U$} & & & \multicolumn{3}{|c|}{ beats $/$ min } & \\
\hline 9.9 & 12.2 & 13.5 & 18.1 & 12.3 & 65 & 60 & 60 & 90 & 60 \\
\hline 14.9 & 21.2 & 16.7 & 18.5 & 10.9 & 65 & 85 & 100 & 105 & 55 \\
\hline 14.0 & 23.8 & 16.8 & 20.4 & 5.9 & 80 & 90 & 108 & 100 & 90 \\
\hline 13.8 & 20.2 & 22.7 & 24.1 & 6.2 & 75 & 75 & 80 & 90 & 80 \\
\hline 15.8 & 24.9 & 26.9 & 30.6 & 6.5 & 65 & 75 & 85 & 102 & 70 \\
\hline 16.4 & 27.3 & 19.6 & 26.6 & 8.7 & 70 & 80 & 85 & 90 & 80 \\
\hline 6.8 & 12.5 & 14.0 & 12.1 & 5.6 & 55 & 70 & 75 & 90 & 70 \\
\hline 7.3 & 11.4 & 9.6 & 8.3 & 3.8 & 75 & 80 & 90 & 110 & 80 \\
\hline 13.1 & 20.8 & 20.8 & 19.7 & 7.0 & 75 & 90 & 105 & 155 & 90 \\
\hline 17.5 & 23.6 & 22.8 & 27.6 & 9.8 & 90 & 95 & 115 & 155 & 110 \\
\hline 11.9 & $18.8^{*}$ & $18.4^{*}$ & $20.2^{*}$ & 7.5 & 68 & 77 & $87^{*}$ & $107^{*}$ & 76 \\
\hline 1.6 & 2.7 & 2.5 & 3.0 & 1.2 & 4.4 & 5.8 & 9.1 & 12.2 & 6.0 \\
\hline 14.0 & $20.7^{*}$ & $18.3^{*}$ & $21.0^{*}$ & $7.9^{*}$ & 75 & 83 & $94^{*}$ & $110^{*}$ & 81 \\
\hline 1.8 & 2.6 & 2.4 & 3.6 & 1.3 & 4.2 & 3.4 & 6.2 & 11.9 & 8.7 \\
\hline
\end{tabular}

\section{RESULTS}

Each patient had more than one manifestation of ascorbic acid deficiency at the time of the first study and the plasma levels of ascorbic acid were markedly reduced (Table II). At the time of the second study, the clinical manifestations of scurvy had disappeared and plasma levels of ascorbic acid had increased.

Resting values of arterial blood pressure, heart rate, central venous pressure, and blood flow to the forearm were similar in the first and second sessions (Tables III, V, and Figs. 3 and 4).

Effect of lower body negative pressure. During session I, LBNP caused a sensation of fainting in two of the five subjects whose mean blood pressures fell by 35 $\mathrm{mm} \mathrm{Hg}(\mathrm{R})$ and $48 \mathrm{~mm} \mathrm{Hg}(\mathrm{Mc})$. The other three subjects had little or no reduction in arterial pressure. During the second session, the largest reduction in arterial pressure was $19 \mathrm{~mm} \mathrm{Hg}$ (S) (Table III). Vascular resistance of the forearm increased during LBNP but the average resistance attained over the $9 \mathrm{~min}$ period of suction was lower in three of the five subjects ( $\mathrm{S}, \mathrm{Mc}$, and $\mathrm{H}$ ) in the first session as compared to the second session.

The tachycardia and the reductions in central venous pressure were similar in the two sessions.

The values of arterial $\mathrm{Po}_{2}, \mathrm{PcO}_{2}, \mathrm{pH}$, hematocrit, and plasma catecholamine concentrations are in Table IV. There were no consistent differences in these values during the two sessions, both before and during LBNP. A slight reduction in $\mathrm{PCO}_{\mathrm{C}}$ took place during LBNP in both sessions.

Responses to intra-arterial infusions of norepinephrine and tyramine. The doses used were insufficient to cause any change in systemic arterial blood pressure or heart 
rate but reductions in blood flow to the forearm were apparent. The responses to both norepinephrine and tyramine were less in session I than in session II (Tables V and VI).

Responses to intravenous infusions of norepinephrine and tyramine. Norepinephrine caused a rise in arterial pressure, a decrease in forearm blood flow, an increase in forearm vascular resistance, and bradycardia in each of the five subjects during session I (Fig. 3). After repletion of ascorbic acid, responses tested in only four of the five subjects were not altered consistently.

During session I tyramine caused a rise in arterial pressure with some increase in blood flow to the forearm, a small increase in forearm vascular resistance, and a decrease in heart rate. These responses were not altered consistently in session II (Fig. 4).

\section{DISCUSSION}

We are reporting in this paper one of several studies which were carried out on five scorbutic men. One of the studies included an evaluation of the tolerance of these men to a cold environment for several hours. They had been deprived of ascorbic acid for a period of 84-97 days and had just started their repletion regimen when one of us $(\mathrm{J} . \mathrm{H}$.) observed that they had an unusual degree of edema of the feet and cyanosis when exposed to the cold. This observation led us to postulate that there may be some alteration in vascular reactivity in human scurvy. After review of the literature, we found several reports which would support the hypothesis that ascorbic acid deficiency might cause an interruption of autonomic cardiovascular reflexes and in particular the adrenergic component of the reflexes. Goldstein, Lauber, Blumberg, and Peisach (6), and Friedman and Kaufman (7) had demonstrated that ascorbic acid was an important cosubstrate involved in the enzymatic synthesis of norepinephrine. The third and last step in the conversion of tyrosine to norepinephrine is the beta-hydroxylation of dopamine which requires copper and the reducing properties of ascorbic acid.

$$
\begin{aligned}
\text { Dopamine } & + \text { ascorbate }+\mathrm{O}_{2} \text { fumarate } \\
& +\mathrm{H}_{2} \mathrm{O}+\text { dehydroascorbate }(7) .
\end{aligned}
$$

On the basis of this finding one may postulate that the rate of synthesis of norepinephrine from dopamine may be reduced in the absence of ascorbic acid. Although defective biosynthesis has not been demonstrated so far in animals deprived of ascorbic acid, Thoa, Wurtman, and Axelrod noted reductions in the catecholamine content of the myocardium of scorbutic guinea pigs (4). Another observation which is probably unrelated to synthesis of the amine is that of Sulkin and Sulkin (8) who demonstrated significant degenerative changes in the ultrastructure of autonomic ganglia of scorbutic guinea pigs; these changes appeared to be specific to the deficiency of this vitamin.

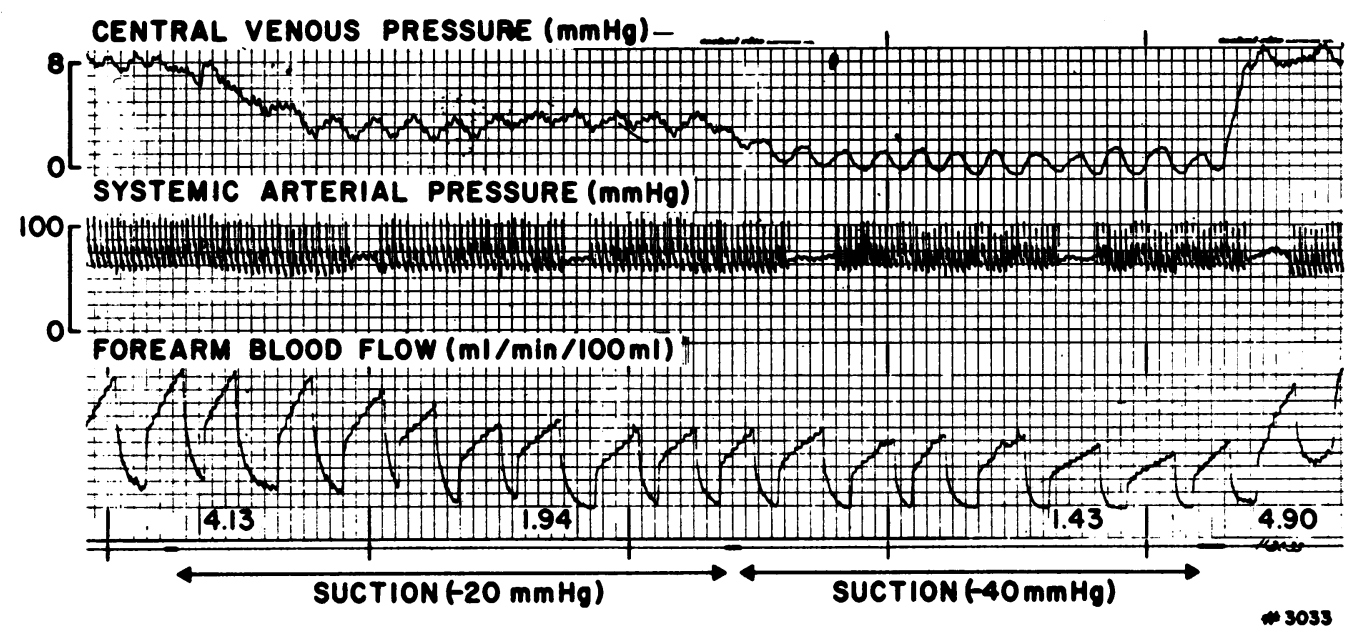

FiguRE 2 Effect of lower body negative pressure (LBNP) on central venous pressure, systemic arterial pressure, and forearm blood flow. For the purpose of this illustration suction was applied at -20 and $-40 \mathrm{~mm} \mathrm{Hg}$ for a total period of approximately $3 \mathrm{~min}$. The fall in central venous pressure and the reduction in blood flow to the forearm were related to the level of negative pressure. The numbers under the flow curves represent the corresponding values of blood flow calculated in $\mathrm{ml} / \mathrm{min}$ per $100 \mathrm{ml}$ of forearm volume. In this experiment mean arterial pressure was unchanged by LBNP but heart rate increased at $-40 \mathrm{~mm} \mathrm{Hg}$. Immediately after the end of suction, blood flow to the forearm increased to levels that were higher than control for a period of approximately $30 \mathrm{sec}$. The distance between two vertical lines represents an interval of $2 \mathrm{sec}$. 

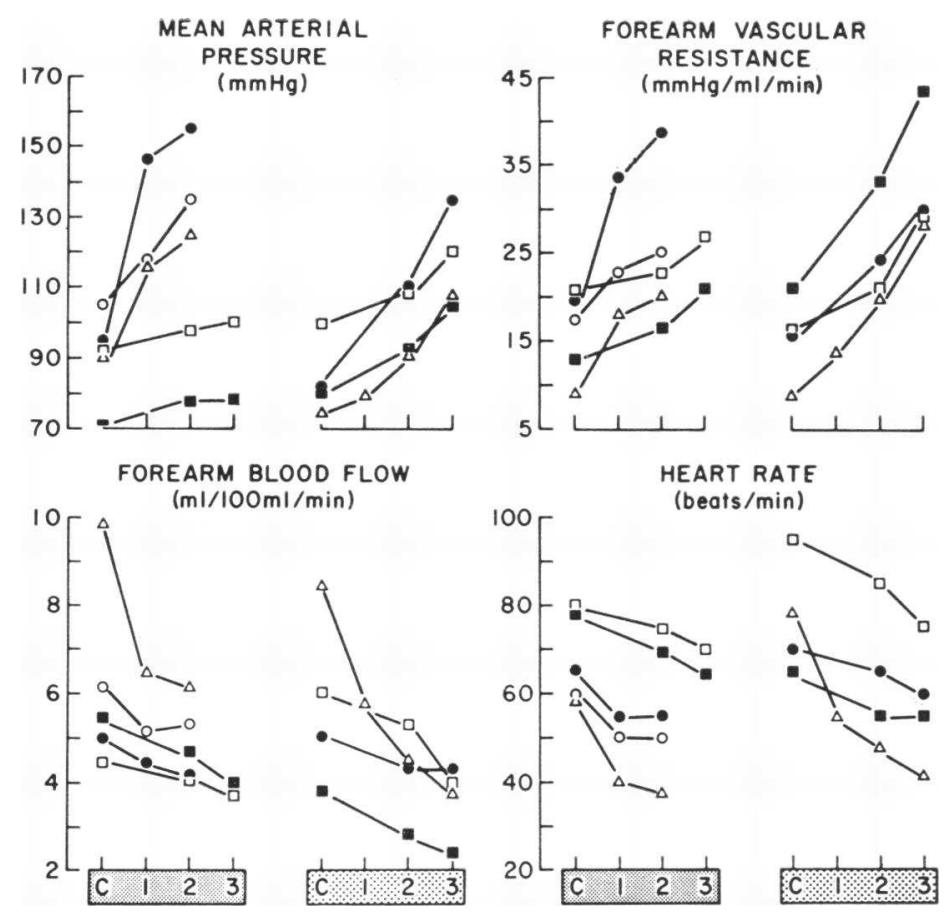

FIGURE 3 Responses to intravenous administration of norepinephrine. Each symbol represents a different subject. C refers to control observations before the infusion and 1,2, and 3 refer to the three doses used $(0.0375,0.075,0.15 \mu \mathrm{g} / \mathrm{kg}$ per $\mathrm{min})$. The values to the left of each graph were obtained during the scorbutic phase (session I) and those to the right were obtained during session II after repletion of ascorbic acid.

We reasoned that if the biochemical and pathophysiological defects which were observed in vitro and in vivo in the guinea pigs occurred also in man we should be able to identify a defect in cardiovascular reflexes in the scorbutic subjects. Such a defect would not necessarily explain the edema and cyanosis that were observed in the cold; but because of its importance and the scarcity of studies on vascular responsiveness in human scurvy, we decided to evaluate the integrity of adrenergic responses in these five subjects who had already become scorbutic. This was done by testing the effects of pooling of blood in the lower extremities and of intra-arterial and intravenous norepinephrine and tyramine. Exposure of the lower half of the body to subatmospheric pressures

\section{TABLE IV}

Blood Gases, pH, Hematocrit, and Plasma Catecholamines in Arterial Blood before $(C)$ and during LBNP (-60 mm Hg) in the Scorbutic Phase (I) and after Repletion of Ascorbic Acid (II)

\begin{tabular}{|c|c|c|c|c|c|c|c|c|c|c|c|}
\hline & & \multicolumn{2}{|c|}{$\mathrm{Po}_{2}$} & \multicolumn{2}{|c|}{$\mathrm{PcO}_{2}$} & \multicolumn{2}{|c|}{$\mathrm{pH}$} & \multicolumn{2}{|c|}{ Hematocrit } & \multicolumn{2}{|c|}{$\begin{array}{c}\text { Plasma } \\
\text { catecholamines }\end{array}$} \\
\hline & & C & LBNP & C & LBNP & $\mathrm{C}$ & LBNP & C & LBNP & $\mathrm{C}$ & LBNP \\
\hline & & & $\mathrm{Hg}$ & & $\mathrm{Hg}$ & & & & cent & & \\
\hline \multirow[t]{2}{*}{ Mean $\pm \mathrm{SE}$} & I & $\begin{array}{r}72.6 \\
4.8\end{array}$ & $\begin{array}{l}62.2 \\
10.8\end{array}$ & $\begin{array}{r}37.4 \\
0.8\end{array}$ & $\begin{array}{c}33.3^{*} \\
1.4\end{array}$ & $\begin{array}{l}7.46 \\
0.011\end{array}$ & $\begin{array}{l}7.47 \\
0.017\end{array}$ & $\begin{array}{r}43.4 \\
2.6\end{array}$ & $\begin{array}{r}43.9 \\
2.2\end{array}$ & $\begin{array}{l}0.68 \\
0.20\end{array}$ & $\begin{array}{l}0.54 \\
0.17\end{array}$ \\
\hline & II & $\begin{array}{r}77.8 \\
4.8\end{array}$ & $\begin{array}{r}80.2 \\
4.7\end{array}$ & $\begin{array}{r}35.1 \\
0.9\end{array}$ & $\begin{array}{c}32.4^{*} \\
0.6\end{array}$ & $\begin{array}{l}7.45 \\
0.004\end{array}$ & $\begin{array}{l}7.45 \\
0.006\end{array}$ & $\begin{array}{r}44.9 \\
2.6\end{array}$ & $\begin{array}{r}44.9 \\
2.3\end{array}$ & $\begin{array}{l}0.43 \\
0.05\end{array}$ & $\begin{array}{l}0.43 \\
0.03\end{array}$ \\
\hline
\end{tabular}

* The average values were significantly different from control (paired $t$ test). Values in sessions I and II were not statistically different. The reduction in $\mathrm{PCO}_{2}$ may reflect some degree of hyperventilation during $\mathrm{LBNP}$. 

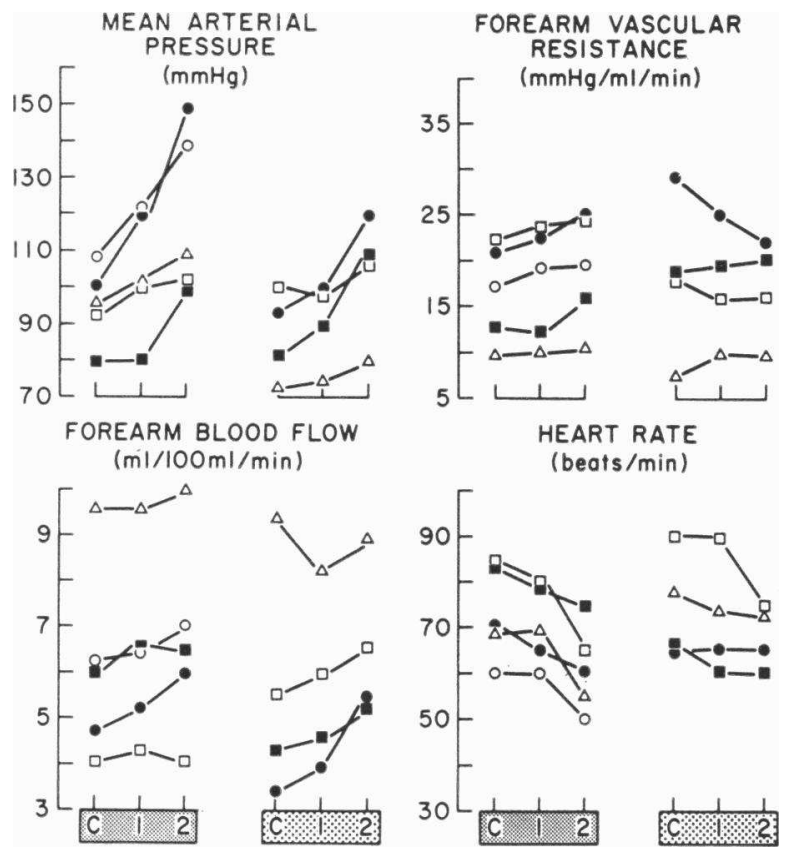

FIGURE 4 Responses to intravenous administration of tyramine (12.5 and $25 \mu \mathrm{g} / \mathrm{kg}$ per $\mathrm{min}$ ). See legend to Fig. 3 .

causes pooling of blood in the lower parts, decreases central venous pressure, and triggers reflex tachycardia and reflex vasoconstriction in the forearm. The responses are similar to those seen during upright tilt (13) ; they reflect to a major degree the integrity of the autonomic nervous system and they are abolished in autonomic neuropathy $(14,15)$. When endogenous catecholamines are depleted, the cardiovascular effects of norepinephrine may be augmented (16) but those of tyramine are reduced since tyramine acts through the release of endogenous catecholamines (17-19). Thus, the relative responses to norepinephrine and tyramine during ascorbic acid deficiency and after its correction provide an indirect index of endogenous catecholamines in these two states.

The results indicate that during the first session when plasma levels of ascorbic acid were negligible and the clinical manifestations of scurvy were evident tachycardia resulted from pooling of blood in the lower extremities and bradycardia was triggered by elevation of arterial pressure with intravenous norepinephrine and tyramine. Similar responses were seen 4 months later during the second session after full repletion of the vitamin and disappearance of all signs and symptoms of the deficiency suggesting that autonomic innervation of the heart was not affected by the vitamin deficiency.

The findings with intra-arterial norepinephrine and tyramine would not support the concept that there is sig- nificant depletion of endogenous catecholamines during experimental scurvy in man. Had there been depletion, the vasoconstrictor response to tyramine would have been reduced and the response to norepinephrine would have been augmented, and this differential effect of the two sympathomimetic amines would have been reversed after repletion of ascorbic acid. The results indicate, however, that the responses to both norepinephrine and tyramine were reduced during ascorbic acid deficiency. Thus, although the vasoconstrictor effect of intraarterial tyramine was reduced in session I as compared to session II, this reduction does not indicate depletion of catecholamines since the vasoconstrictor effect of intra-arterial norepinephrine, which acts directly on adrenergic alpha receptors, was also reduced in session I. The decreased responsiveness should therefore be attributed to either a nonspecific reduction in contractility of vascular smooth muscle in scurvy or a diminution in responsiveness to adrenergic stimuli. In their studies on mesenteric vessels of scorbutic guinea pigs, Lee and Lee reported decreased responsiveness of venules and arterioles less than $100 \mu$ in topical applications of epinephrine; the responsiveness of larger vessels was not altered (2).

The levels of arterial pressure and of forearm vascular resistance which were attained during LBNP also suggest that the responsiveness of resistance vessels of the forearm to LBNP was less in session I than in session II in four of the five subjects. Two subjects ( $R$ and Mc) had marked reductions in arterial blood pressure accompanied by a sensation of dizziness and fainting during LBNP in session I. These effects were not seen after repletion of ascorbic acid; and although the levels of vascular resistance of the forearm were not consistently lower during LBNP in session I in these two subjects, the more pronounced hypotension would indicate that vascular tone was less during $L B N P$ in session $I$ than in session II. Two other subjects ( $\mathrm{S}$ and $\mathrm{H}$ had lower levels of vascular resistance associated with slightly lower levels of pressure during LBNP in session I than in session II suggesting also that vascular tone was less during LBNP in the first session.

The constrictor effects of intravenous norepinephrine and tyramine on resistance vessels of the forearm were not augmented consistently after repletion of ascorbic acid as were the responses to the intra-arterial infusions. It should be mentioned in this connection that responses to intravenous infusions include in addition to the direct action of the drugs on blood vessels a possible central action or myogenic and neurogenic reflex effects which may either mask, modify, or override any direct effects.

Deprivation from ascorbic acid was maintained for a period of 3 months. It might be argued that this period was insufficient to induce scurvy in view of previous 
studies in which the deficiency had to be maintained for more than 4 months before the appearance of symptoms and signs of scurvy $(20-23)$. In this as in previous studies by our group $(9,10,24)$, the 3 month period was sufficient to decrease the total body pool of ascorbic acid to less than $20 \%$, to decrease the plasma levels to less than $0.1 \mathrm{mg} / 100 \mathrm{ml}$ in most subjects and to cause definite clinical manifestations of scurvy. Rigid dietary restriction may have been a factor in our ability to induce scurvy in a shorter period of time than was possible in earlier studies.

In the present experiments, session I was held 3-10 days after the beginning of repletion of ascorbic acid rather than at the end of the depletion phase. The reason was that the clinical observation which led to the studies on vascular responsiveness was made at the end of the period of depletion and during the first few days of repletion as was mentioned in the foregoing text. The short period of repletion did not affect the scorbutic state of these men; and at the time of the first study, the clinical manifestations were as pronounced as on the last day of depletion and the plasma levels of ascorbic acid were still very low. Subject Mc who had had the largest amount of supplemental ascorbic acid at the time of the first study also had the greatest reduction in vasoconstrictor responses to $\mathrm{LBNP}$ as compared to responses obtained 4 months later.

The degree to which the vasoconstrictor responses were augmented after the 4 month repletion period did not appear to correlate with the dose of supplemental ascorbic acid that had been administered; a dose of 10 $\mathrm{mg} /$ day or less may well exceed the requirements for maintaining or restoring "normal" vasomotor responsiveness.

Perhaps the most important conclusion which can be drawn from these findings is that experimental scurvy in man is not accompanied by the physiologic or pharmacologic responses which would be associated with degeneration of autonomic ganglia or with defective synthesis of norepinephrine. The in vitro biochemical findings and the observations made on autonomic ganglia of scorbutic guinea pigs may not be transferable to experimental human scurvy. In this regard, however, one should mention that enzymatic beta-hydroxylation of dopamine to norepinephrine is not a rate-limiting step in the synthesis of the neuromediator (25), and there-

TABLE V

Effect of Intra-Arterial Infusions of Norepinephrine and Tyramine on Blood Flow to the Forearm (ml/min per $100 \mathrm{ml})$ during the Scorbutic Phase (I) and after Repletion of Ascorbic Acid (II)

\begin{tabular}{|c|c|c|c|c|c|c|c|}
\hline \multirow[t]{3}{*}{ Subject } & & $\mathrm{C}$ & \multicolumn{2}{|c|}{ Norepinephrine } & $\mathrm{C}$ & \multicolumn{2}{|c|}{ Tyramine } \\
\hline & & & \multicolumn{2}{|c|}{$\mu g / k g$ per min } & & \multicolumn{2}{|c|}{$\mu g / k g$ per min } \\
\hline & & & 0.002 & 0.004 & & 0.3 & 0.6 \\
\hline \multirow[t]{2}{*}{$\mathrm{H}$} & I & 7.5 & 3.3 & 2.8 & 7.8 & 5.5 & 4.0 \\
\hline & II & 9.8 & 2.5 & 1.4 & 8.1 & 5.3 & 4.9 \\
\hline \multirow[t]{2}{*}{ Mc } & I & 4.3 & 2.6 & 2.1 & 5.3 & 4.2 & 2.9 \\
\hline & II & 4.3 & 2.0 & 1.4 & 4.2 & 2.3 & 1.2 \\
\hline \multirow[t]{2}{*}{$\mathrm{R}$} & I & 5.2 & 2.9 & 2.4 & 5.7 & 3.6 & 2.3 \\
\hline & II & 4.0 & 1.0 & 0.8 & 5.9 & 2.5 & 1.8 \\
\hline \multirow[t]{2}{*}{$\mathrm{P}$} & I & 11.3 & 5.1 & 2.0 & 11.3 & 7.6 & 5.2 \\
\hline & II & 7.0 & 1.6 & 1.5 & 6.2 & 4.0 & 3.5 \\
\hline \multirow[t]{2}{*}{$\mathrm{S}$} & I & 4.7 & 4.3 & 3.5 & 4.3 & 3.8 & 3.3 \\
\hline & II & 4.0 & 1.7 & 1.8 & 4.1 & 2.2 & 1.8 \\
\hline \multirow[t]{4}{*}{ Mean $\pm \mathrm{SE}$} & I & 6.60 & $3.64^{*}$ & $2.56^{*}$ & 6.88 & $4.94^{*}$ & $3.54^{*}$ \\
\hline & & 1.29 & 0.46 & 0.27 & 1.24 & 0.74 & 0.50 \\
\hline & II & 5.82 & $1.76^{*}$ & $1.38^{*}$ & 5.70 & $3.26^{*}$ & $2.64^{*}$ \\
\hline & & 1.14 & 0.24 & 0.16 & 0.74 & 0.60 & 0.68 \\
\hline \multicolumn{2}{|c|}{$P$ values $\ddagger$ Ivs $/ I I$} & $>0.05$ & \multicolumn{2}{|c|}{$<0.005$} & $>0.05$ & \multicolumn{2}{|c|}{$<0.05$} \\
\hline
\end{tabular}

* Indicates that the values during infusions were significantly different from control $(P<0.05$ by paired $t$ test $)$.

$\ddagger$ Indicates the probability values for the statistical significance of the differences between sessions I and II which were calculated by paired $t$ test for control values (C) and by analysis of variance (Table VI) for values obtained during the infusions. 
TABLE VI

Analysis of Variance of Responses to Intra-Arterial Norepinephrine and

Tyramine in the Two Sessions

\begin{tabular}{|c|c|c|c|c|c|}
\hline \multirow[b]{2}{*}{ Source of variation } & \multirow[b]{2}{*}{$\begin{array}{l}\text { Degrees of } \\
\text { freedom }\end{array}$} & \multicolumn{2}{|c|}{ Norepinephrine } & \multicolumn{2}{|c|}{ Tyramine } \\
\hline & & $\begin{array}{l}\text { Mean } \\
\text { square }\end{array}$ & $\mathbf{F}$ & $\begin{array}{l}\text { Mean } \\
\text { square }\end{array}$ & F \\
\hline Subjects & 4 & 0.68 & 1.67 & 6.62 & $12.97^{*}$ \\
\hline Sessions & 1 & 11.76 & $29.18^{*}$ & 8.32 & $16.31^{*}$ \\
\hline Doses & 1 & 2.56 & $6.35 \ddagger$ & 5.10 & $10.00 \ddagger$ \\
\hline Sessions $\times$ Doses & 1 & 0.66 & 1.64 & 0.76 & 1.49 \\
\hline Error & 12 & 0.403 & & 0.510 & \\
\hline
\end{tabular}

* Indicates $P<0.005$ and the absence of a symbol indicates that the $\mathrm{F}$ value was not statistically significant (Snedecor, G. W. 1956. Statistical Methods Applied to Experiments in Agriculture and Biology, Iowa State University Press, Ames, edition 5). The significance of the variation ascribed to "Sessions" indicates that responses to the sympathomimetic amines were different in the two sessions and the significance of the variation of "Doses" indicates that there was a dose-related effect. The lack of significance of the variation ascribed to Sessions $\times$ Doses interactions indicates that the dose-response curves in the two sessions were parallel.

$\ddagger$ Indicates $P<0.05$.

fore, a deficiency of ascorbic acid which is important for that step might not be expected to result in significant reductions in the synthesis of endogenous norepinephrine. In guinea pigs, scurvy may be induced within 2-3 wk and the metabolic pathways of ascorbic acid are different in pigs and in man so that the pathophysiology of scurvy may be different in the two species.

\section{ACKNOWLEDGMENTS}

This study was supported by research grants from the American and Iowa Heart Associations, the U. S. Public Health Service (HE-09835, HE-02644, and TI-AM5306), by a U. S. Army Medical Research and Development Command Contract (DADA17-67-C-7111), and by a Research Career Program Award HE-K3-17013 from the U. S. Public Health Service.

\section{REFERENCES}

1. Abboud, F. M., J. Hood, and R. E. Hodges. 1968. Vascular reactivity in experimental scurvy in man. $J$. Lab. Clin. Med. 72: 849. (Abstr.)

2. Lee, R. E., and N. Z. Lee. 1947. The peripheral vascular system and its reactions in scurvy: an experimental study. Amer. J. Physiol. 149: 465.

3. Thoa, N. B., and W. M. Booker. 1963. Cardiovascular dynamics in normal and scorbutic guinea pigs infused with dopamine and norepinephrine. Fed. Proc. 22: 448. (Abstr.)

4. Thoa, N. B., R. J. Wurtman, and J. Axelrod. 1966. A deficient binding mechanism for norepinephrine in hearts of scorbutic guinea pigs. Proc. Soc. Exp. Biol. Med. $121: 267$.

5. Bhagat, B., W. L. West, and I. M. Robinson. 1966. Sensitivity to norepinephrine of isolated atria from scorbutic guinea pigs. Biochem. Pharmacol. 15: 1637.
6. Goldstein, M., E. Lauber, W. E. Blumberg, and J. Peisach. 1965. Dopamine- $\beta$-hydroxylase-a copper enzyme. $F e d$. Proc. 24: 604. (Abstr.)

7. Friedman, S., and S. Kaufman. 1965. 3,4-Dihydroxyphenylethylamine $\beta$-hydroxylase: a copper protein. $J$. Biol. Chem. 240: PC552.

8. Sulkin, D. F., and N. M. Sulkin. 1967. An electron microscopic study of autonomic ganglion cells of guinea pigs during ascorbic acid deficiency and partial inanition. Lab. Invest. 16: 142.

9. Hodges, R. E., E. M. Baker, J. Hood, H. E Sauberlich, and S. C. March. 1969. Experimental scurvy in man. Amer. J. Clin. Nutr. 22: 535.

10. Baker, E. M., R. E. Hodges, J. Hood, H. E. Sauberlich, and S. C. March. 1969. Metabolism of ascorbic-1 ${ }^{14} \mathrm{C}$ acid in experimental human scurvy. Amer. J. Clin. Nutr. 22: 549 .

11. Whitney, R. J. 1953. The measurement of volume changes in human limbs. J. Physiol. (London). 121: 1.

12. Wood, J. E. 1965. The Veins; Normal and Abnormal Function. Little, Brown and Company, Boston. 62-65.

13. Brigden, W., S. Howarth, and E. N. Sharpey-Schafer. 1950. Postural changes in the peripheral blood flow of normal subjects with observations on vasovagal fainting reactions as a result of tilting, lordotic posture, pregnancy and spinal anesthesia. Clin. Sci. 9: 78.

14. Mason, D. T., I. J. Kopin, and E. Braunwald. 1966. Abnormalities in reflex arterial and venous constriction to changes in posture in familial dysautonomia. Circulation. 34 (Suppl. 3) : 164.

15. Abboud, F. M., and J. W. Eckstein. 1966. Autonomic defect in orthostatic hypotension. J. Lab. Clin. Med. 68: 851. (Abstr.)

16. Burn, J. H., and M. J. Rand. 1958. The action of sympathomimetic amines in animals treated with reserpine. J. Physiol. (London). 144: 314.

17. Trendelenburg, U. 1961. Modification of the effect 
of tyramine by various agents and procedures. J. Pharmacol. Exp. Ther. 134: 8-17.

18. Abboud, F. M., and J. W. Eckstein. 1964. Effects of small oral doses of reserpine on vascular responses to tyramine and norepinephrine in man. Circulation. 29: 219.

19. Abboud, F. M., and J. W. Eckstein. 1964. Venous and arterial responses to norepinephrine in dogs treated with reserpine. Amer. J. Physiol. 206: 299.

20. Medical Research Council. Vitamin-C subcommittee of the accessory food factors committee. R. A. Peters, Chairman. 1948. Vitamin-C requirement of human adults. Experimental study of vitamin-C deprivation in man. Preliminary report. Lancet. 1: 853 .
21. Crandon, J. H., C. C. Lund, and D. B. Dill. 1940. Experimental human scurvy. N. Engl. J. Med. 223: 353. 22. Farmer, C. J. 1944. Some aspects of vitamin C metabolism. Fed. Proc. 3: 179.

23. Pijoan, M., and E. L. Lozner. 1944. Vitamin C economy in the human subject. Bull. Johns Hopkins Hosp. 75: 303.

24. Hood, J., and R. E. Hodges. 1969. Ocular lesions in scurvy. Amer. J. Clin. Nutr. 22: 559.

25. Nikodijevic, B., C. R. Creveling, and S. Udenfriend. 1963. Inhibition of dopamine beta-oxidase in vivo by benzyloxyamine and benzylhydrazine analogs. J. Pharmacol. Exp. Ther. 140: 224. 